\title{
Pemilihan Prioritas Wilayah Penanganan Genangan Air Dengan Metode Analytic Hierarchy Process (AHP) Di Kota Dumai
}

\author{
M. Ridwan Putra \\ Program Studi Teknik Sipil, Universitas Riau \\ Jl. Bina Widya KM 25 Kota Pekanbaru, Kode Pos 28293 \\ E-mail : ridwan_putra@yahoo.co.id
}

\begin{abstract}
ABSTRAK
Banyaknyanya lokasi genangan air di Kota Dumai membuat para pengambil keputusan ragu-ragu dalam mengambil keputusan. Prioritas penanganan genangan yang paling tepat memerlukan data akurat berbasis komputer sebagai dasar setiap keputusan yang akan dilaksanakan. Penelitian ini dilakukan dengan cara survei dan metode literatur yang bertujuan untuk mengidentifikasi parameter-parameter yang berpengaruh terhadap nilai prioritas penanganan dengan metode Analytical Hierarchy Process (AHP) yang berdasarkan kriteria Teknis, Ekonomi, Lingkungan, dan Sosial/Budaya.Dari hasil penelitian yang telah dilakukan, maka dapat diketahui bahwa kriteria yang memiliki prioritas (tingkat) paling mempengaruhi terhadap penentuan prioritas wilayah penanganan genangan air adalah kriteria teknis $(42,7 \%)$ dan kriteria lingkungan (29,2\%). Sub kriteria parameter yang paling berpengaruh dalam penentuan prioritas wilayah penanganan genangan air adalah perubahan tata guna lahan dengan persentase sebesar 64,9\%. Berdasarkan hasil analisa Analytical Hierarchy Process (AHP), diperoleh wilayah terbaik untuk rencana penanganan genangan air di Kota Dumai adalah Jalan Sultan Syarif Qasim dengan persentase sebesar $38,3 \%$. Upaya yang dilakukan untuk penanganan genangan drainase di Jl. Sultan Syarif Qasim adalah dengan memperbaiki sistem drainase eksisting. Rencana mitigasi genangan air di wilayah yang menjadi prioritas adalah dengan pelebaran drainase menjadi ukuran 2,5 x 1,6 m untuk mengatasi genangan air yang terjadi.
\end{abstract}

Kata kunci: Genangan, Penanganan, Prioritas, Strategi, Dumai

\begin{abstract}
A large number of puddles in Dumai City makes decision makers hesitant in making decisions. The most appropriate priority for inundation requires computer-based accurate data as the basis for every decision to be made. This research was conducted by survey and literature method which aims to identify parameters that influence the priority value of handling by the Analytical Hierarchy Process (AHP) based on Technical, Economic, Environmental, and Social / Cultural criteria. From the results, it can be seen that the requirements of the research that have the most influence (level) on the determination of priority areas for handling inundation are technical criteria $(42.7 \%)$ and environmental criteria (29.2\%). The most influential parameter subcriteria in determining the priority of waterlogging areas is the change in land use

UNITEK Vol 12 No.1 Januari - Juni 2019 | p-ISSN 2089-3957 | e-ISSN 2580-2585
\end{abstract}


with a percentage of $64.9 \%$. Based on the analysis of the Analytical Hierarchy Process $(A H P)$, the best area for the plan for handling standing water in Dumai City is Jalan Sultan Syarif Qasim with a percentage of 38.3\%. Efforts made for handling drainage inundation on Jl. Sultan Syarif Qasim is by improving the existing drainage system. The mitigation plan for standing water in the priority area is by widening drainage to a size of $2.5 \times 1.6 \mathrm{~m}$ to overcome the inundation that occurs.

Keywords: Inundation, Handling, Priority, Strategy, Dumai

\section{Pendahuluan}

Permasalahan drainase di Kota Dumai sangat kompleks antara lain dikarenakan kondisi topografi Dumai yang tingkat leveling relatif datar dan sebagian daerah memiliki permukaan yang lebih rendah dari permukaan laut, perencanaan pembangunan yang tidak terkoordinir sehingga kebanyakan drainase penggunaannya tidak optimal lagi serta desain drainase yang tidak sesuai dengan kawasan tangkapan air dan debit air yang melewati saluran tersebut. Keadaan tersebut diperburuk karena banyak drainase lingkungan yang beralih fungsi sebagai penampungan limbah rumah tangga sehingga menyebabkan pencemaran terlebih lagi sampah-sampah rumah tangga menjadi salah satu penyebab penyumbatan drainase yang mengganggu dan menghambat aliran air (Juliswan, 2016).

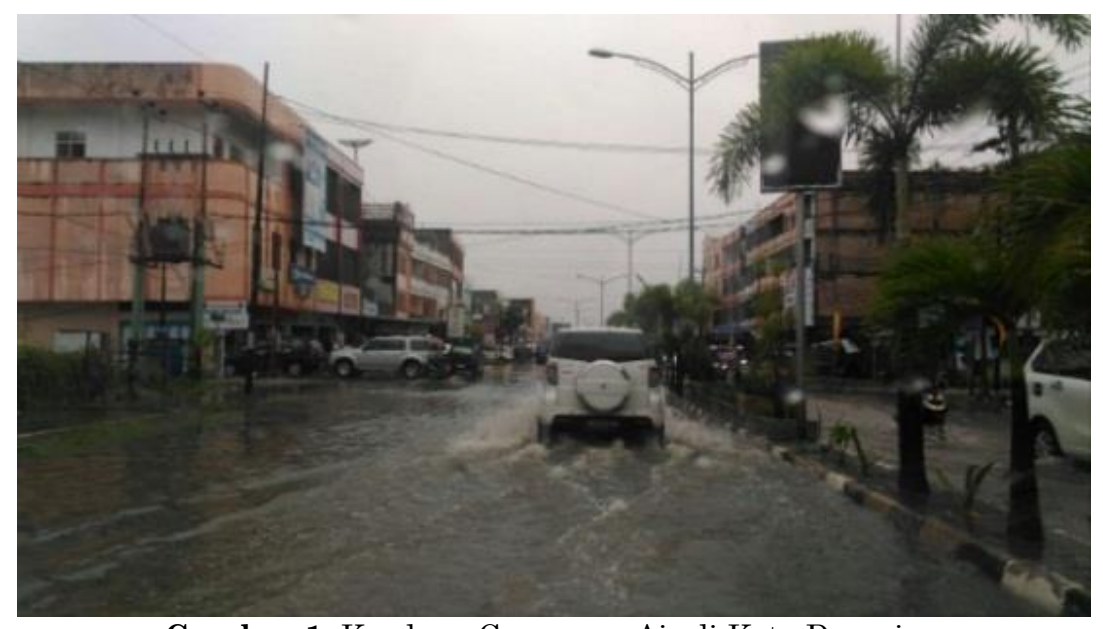

Gambar 1. Keadaan Genangan Air di Kota Dumai

Kota Dumai merupakan wilayah tepi pantai yaitu berada di tepi Selat Rupat, khususnya wilayah bagian Utara yang mencakup Kecamatan Dumai Barat dan Dumai Timur. Wilayah Utara Kota Dumai tersebut merupakan dataran rendah dengan ketinggian 1,3-6,3 m dpl dan kemiringan lahan $0-3 \%$. Dengan posisi ketinggian lahan yang rendah dan dekat pantai, menyebabkan wilayah bagian Utara Kota Dumai terancam rawan terserang genangan (BPS, 2017). Dengan melihat fakta tersebut, maka diperlukan adanya kegiatan yang bersifat antisipasi (prefentif) yang lebih terpadu dari pemerintah daerah kepada masyarakat yang sering terkena dampak genangan air dengan cara skala prioritas pembangunan atau rehabilitasi

UNITEK Vol 12 No.1 Januari - Juni 2019 | p-ISSN 2089-3957 | e-ISSN 2580-2585 
sistim drainase Kota Dumai. Prioritas penanganan genangan yang paling tepat memerlukan data akurat berbasis komputer sebagai dasar setiap keputusan yang akan dilaksanakan.

Salah satu solusi tersebut adalah dibantu dengan analisa komputer secara kuantitatif yaitu dengan menyusun skala prioritas dengan menggunakan metode algoritma Analytical Hierarchy Process (AHP). Dengan memperhatikan latar belakang dan rumusan masalah, Adapun tujuan penelitian ini sebagai berikut:

1. Mengetahui faktor-faktor dan parameter apa saja yang paling berpengaruh terhadap kinerja sistim drainase yang berpengaruh terjadinya genangan ditinjau dari segi teknis, dampak sosial, dampak lingkungan dan pembiayaan.

2. Mengetahui dan menentukan prioritas penanganan dan penyelesaian dampak genangan di Kota dumai.

3. Mengetahui dan menyusun strategi teknis penaganan yang harus dilakukan untuk memaksimalkan fungsi dan kinerja sistim saluran yang akan dibangun atau direhabilitasi.

Penulis membahas satu dari berbagai metoda sistim pendukung pengambilan keputusan yakni metode Analytical Hierarchy Process (AHP) untuk mengkaji pengambilan keputusan berdasarkan skala prioritas pembangunan atau rehabilitasi sistim drainase Kota Dumai.

\section{Metode Penelitian}

Penelitian dilakukan di Kota Dumai. Adapun penelitian ini adalah sebagai berikut.

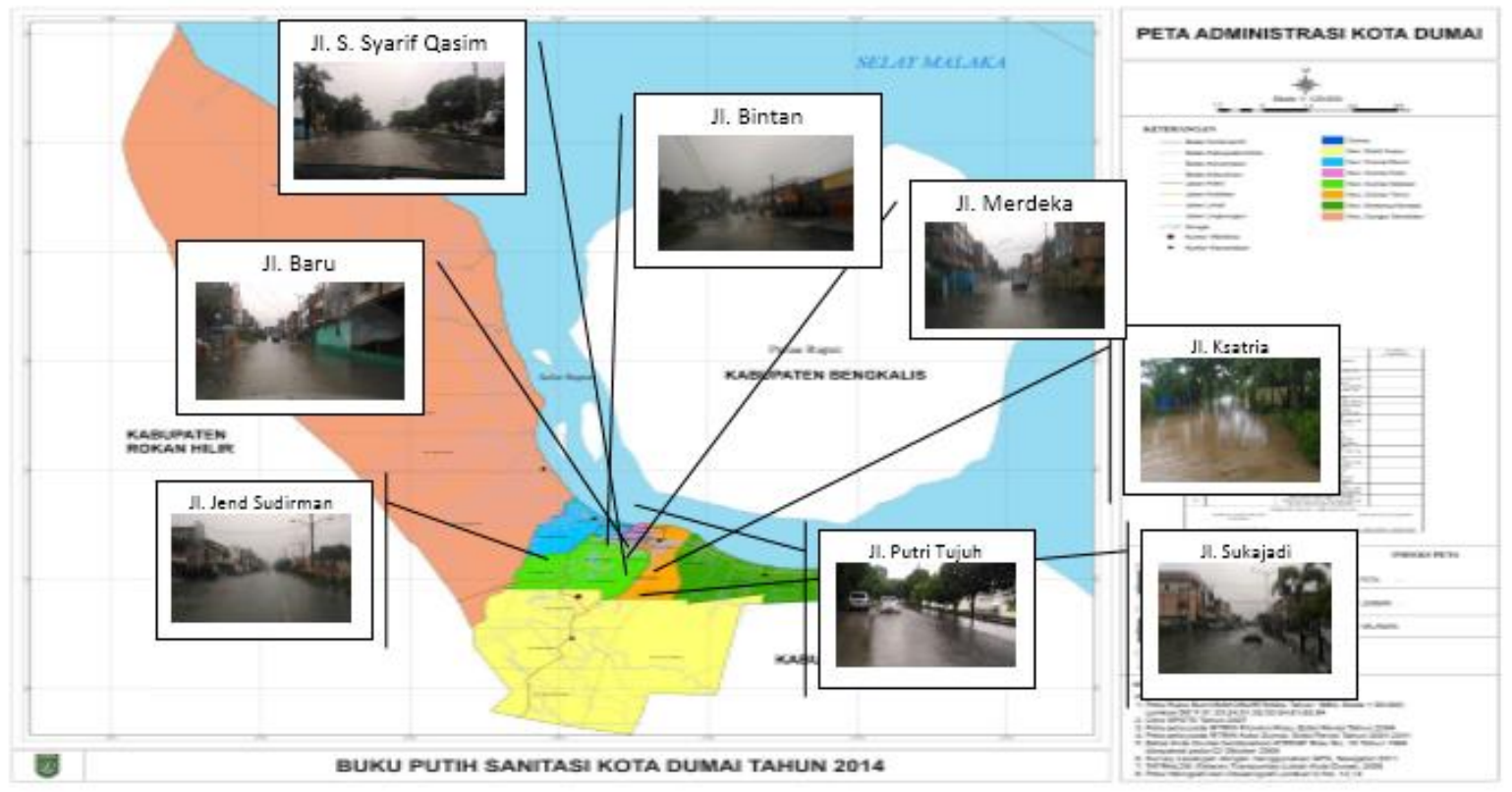

Gambar 2. Lokasi Titik Genangan Kota Dumai

UNITEK Vol 12 No.1 Januari - Juni 2019

| p-ISSN 2089-3957 | e-ISSN 2580-2585 
Data yang digunakan dalam penelitian ini berupa data primer dan data sekunder. Data primer adalah data kuisioner Analytical Hierarchy Process (AHP). Penelitian yang dilakukan adalah menggunakan metode survei dengan cara menyebarkan kuisioner kepada responden, sehingga perlu dirancang model kuisioner yang akan digunakan. Tahapan penelitian ini menggambarkan proses pengumpulan data dan mempelajari data, dimana data yang diperlukan adalah data primer dan data sekunder. Melakukan survey lapangan, dilakukan sebelum penelitian agar bertujuan untuk mengetahui kondisi genangan di Kota Dumai.

\section{Hasil dan Pembahasan}

\section{Analisis Kriteria Signifikan Dalam Pengambilan Keputusan Pemilihan Prioritas Wilayah Penanganan Genangan Air di Kota Dumai}

Survei pendahuluan ini dilakukan pada tanggal 10 April 2017 selama 2 minggu. Survei dilakukan dengan menyebarkan 10 kuisioner kepada beberapa instansi yaitu Dinas Pekerjaan Umum Cipta Karya dan Sumber Daya Air Kota Dumai, BAPPEDA Kota Dumai, Dinas Perumahan Rakyat dan Kawasan Pemukiman Kota Dumai, Sekolah Tinggi Teknologi Kota Dumai, Konsultan dan Kontraktor yang biasa bergerak dibidang sumber daya air.

Tabel 1. Nama Responden

\begin{tabular}{|c|l|l|}
\hline No & \multicolumn{1}{|c|}{ Nama Responden } & \multicolumn{1}{c|}{ Jabatan } \\
\hline 1 & Riau Satrya Alamsyah ST & Kepala Bidang Cipta karya Dinas PU Kota Dumai \\
\hline 2 & Yomi Idriansyah ST & Kepala seksi tata bangunan Dinas PU Kota Dumai \\
\hline 3 & Ir. Zulkarnain, M.Si & BAPPEDA \\
\hline 4 & Ir. H. M Nasir & Sekda Kota Dumai \\
\hline 5 & Muhammad Mufarizal, ST & Kepala Bidang kawasan permukiman \\
\hline 6 & M. Syafei & BAPPEDA \\
\hline 7 & Fauzia Rahmi, ST & $\begin{array}{l}\text { Kepala Seksi Pencegahan Peningkatan Kualitas, } \\
\text { Pemanfaatan dan Pengendalian }\end{array}$ \\
\hline 8 & Sony adiya Putra, MT & Dosen STT Kota Dumai \\
\hline 9 & Suherman, ST & Konsultan \\
\hline 10 & Eko Suprianto & Kontraktor \\
\hline
\end{tabular}

Kumpulan data kuisioner pendahuluan dianalisis dengan menggunakan nilai pembobotan (scoring card), yaitu perkalian terhadap tingkat pengaruh dengan jumlah pilihan. Untuk masing-masing kriteria dipilih 3 sub kriteria yang terbesar. Hasilnya dapat dilihat pada Tabel 2.

UNITEK Vol 12 No.1 Januari - Juni 2019 | p-ISSN 2089-3957 | e-ISSN 2580-2585 
Tabel Error! No text of specified style in document.2. Hasil analisis survey pendahuluan

\begin{tabular}{|c|c|c|c|c|c|c|}
\hline & \multirow[t]{2}{*}{ Tinjauan Parameter Prioritas Wilayah Penanganan Genangan Air } & \multicolumn{4}{|c|}{$\begin{array}{c}\text { Tingkat } \\
\text { Pengaruh } \\
\text { Parameter } \\
\text { yang Paling } \\
\text { Penting } \\
\text { Terhadap } \\
\text { Wilayah } \\
\text { Penanganan } \\
\text { Genangan } \\
\text { Air }\end{array}$} & \multirow[t]{2}{*}{ Skor } \\
\hline & & 1 & 2 & 3 & 4 & \\
\hline \multicolumn{7}{|c|}{ TEKNIS } \\
\hline 1 & Kondisi Fisik dan Fungsi Drainase & 0 & 0 & 4 & 6 & 36 \\
\hline 2 & Kapasitas Jaringan Drainase & 0 & 0 & 5 & 5 & 35 \\
\hline 3 & Kondisi Infrastruktur Jalan & 0 & 4 & 4 & 2 & 28 \\
\hline 4 & Karakteristik Genangan Air & 1 & 3 & 5 & 1 & 26 \\
\hline 5 & Kesesuaian Drainase Jalan & 0 & 5 & 4 & 1 & 26 \\
\hline 6 & Koordinasi dengan Dinas Terkait (PU / Camat / Lurah) & 0 & 3 & 4 & 3 & 30 \\
\hline 7 & Perubahan Tata Guna Lahan & 0 & 0 & 7 & 3 & 33 \\
\hline 8 & Kinerja Daerah Resapan & 0 & 2 & 4 & 4 & 32 \\
\hline \multicolumn{7}{|c|}{ EKONOMI } \\
\hline 9 & Biaya Pekerjaan Pembangunan Sistem Drainase & 0 & 1 & 7 & 2 & 31 \\
\hline 10 & Ketersediaan Dana Operasi \& Pemeliharaan Tahunan Sistem Drainase & 0 & 1 & 4 & 5 & 34 \\
\hline 11 & Biaya Evaluasi Monitoring Tahunan Sistem Drainase & 0 & 3 & 4 & 3 & 30 \\
\hline \multicolumn{7}{|c|}{ LINGKUNGAN } \\
\hline 12 & Kepadatan Lalu Lintas & 0 & 2 & 7 & 1 & 29 \\
\hline 13 & Sanitasi Lingkungan & 0 & 3 & 2 & 5 & 32 \\
\hline 14 & Luas Daerah Layanan & 0 & 2 & 2 & 6 & 34 \\
\hline 15 & Volume Sampah & 0 & 0 & 4 & 6 & 36 \\
\hline 16 & Pencemaran Air Permukaan & 0 & 0 & 3 & 7 & 37 \\
\hline 17 & Wilayah Pengembangan & 0 & 1 & 3 & 6 & 35 \\
\hline \multicolumn{7}{|c|}{ SOSIAL BUDAYA } \\
\hline 18 & Kepedulian dan Keterlibatan Masyarakat & 0 & 2 & 5 & 3 & 31 \\
\hline 19 & Pengelolaan dan Pemeliharaan Prasarana Drainase & 0 & 3 & 4 & 3 & 30 \\
\hline 20 & Perilaku Membuang Sampah Sembarangan & 0 & 0 & 7 & 3 & 33 \\
\hline 21 & Berkurangnya Produktivitas Kerja & 0 & 5 & 2 & 3 & 28 \\
\hline 22 & Penegakan Hukum/ Aturan & 0 & 0 & 4 & 6 & 36 \\
\hline
\end{tabular}

Analisis deskriptif bertujuan untuk mengetahui seberapa besarnya tingkat pengaruh parameter tersebut dalam penentuan prioritas genangan air di Kota Dumai. Berikut ini hasil analisis secara deskriptif terhadap tingkat pengaruh dari sub kriteria parameter tersebut berdasarkan distribusi frekuensi. Penentuan distribusi frekuensi didasarkan pada nilai intervalnya, sehingga untuk memperoleh distribusi frekuensi tersebut terlebih dahulu harus ditentukan nilai intervalnya dengan formulasi sebagai berikut (Purbawijaya, 2012):

$$
\text { Interval }=\frac{\text { Nilai Tertinggi }- \text { Nilai Terendah }}{\text { Jumlah Kelas }}
$$

Mengingat skor untuk masing-masing penilaian sub kriteria dari penelitian adalah minimal 1 dan maksimal 4, maka dapat dihitung interval sebagai berikut:

$$
\text { Interval }=\frac{4-1}{4}=0,75
$$

UNITEK Vol 12 No.1 Januari - Juni 2019 | p-ISSN 2089-3957 | e-ISSN 2580-2585 
Untuk mengetahui kondisi sub kriteria dari parameter penelitian secara menyeluruh akan dilihat dari rata-rata skor dengan kriteria sebagai berikut (Purbawijaya, 2012):
$1,00-1,75$
= Tidak berpengaruh
$1,76-2,50=$ Cukup berpengaruh
$2,51-3,25=$ Berpengaruh
$3,26-4,00=$ Sangat Berpengaruh

Tabel Error! No text of specified style in document.3. Hasil tanggapan responden berdasarkan analisis deskriptif

\begin{tabular}{|c|c|c|}
\hline Parameter & $\begin{array}{l}\text { Rata-Rata } \\
\text { Skor }\end{array}$ & Keterangan \\
\hline \multicolumn{3}{|c|}{ TEKNIS } \\
\hline Kondisi Fisik dan Fungsi Drainase & 3,60 & Sangat Berpengaruh \\
\hline Kapasitas Jaringan Drainase & 3,50 & Sangat Berpengaruh \\
\hline Perubahan Tata Guna Lahan & 3,30 & Sangat Berpengaruh \\
\hline \multicolumn{3}{|c|}{ EKONOMI } \\
\hline $\begin{array}{l}\text { Biaya Pekerjaan Pembangunan Sistem } \\
\text { Drainase }\end{array}$ & 3,10 & Berpengaruh \\
\hline $\begin{array}{l}\text { Ketersediaan Dana Operasi \& } \\
\text { Pemeliharaan Tahunan Sistem Drainase }\end{array}$ & 3,40 & Sangat Berpengaruh \\
\hline $\begin{array}{l}\text { Biaya Evaluasi Monitoring Tahunan } \\
\text { Sistem Drainase }\end{array}$ & 3,00 & Berpengaruh \\
\hline \multicolumn{3}{|c|}{$\begin{array}{ll}\text { LINGKUNGAN } \\
\end{array}$} \\
\hline Sanitasi Lingkungan & 3,20 & Berpengaruh \\
\hline Luas Daerah Layanan & 3,40 & Sangat Berpengaruh \\
\hline Volume Sampah & 3,60 & Sangat Berpengaruh \\
\hline \multicolumn{3}{|c|}{ SOSIAL/BUDAYA } \\
\hline $\begin{array}{l}\text { Pengelolaan dan Pemeliharaan } \\
\text { Prasarana Drainase }\end{array}$ & 3,00 & Berpengaruh \\
\hline $\begin{array}{l}\text { Prilaku Membuang Sampah } \\
\text { Sembarangan }\end{array}$ & 3,30 & Sangat Berpengaruh \\
\hline Penegakan hukum/aturan & 3,60 & Sangat Berpengaruh \\
\hline
\end{tabular}

Pengambilan sampel dengan cara Analytical Hierarchy Process (AHP) pada tahap ini menggunakan responden yang merupakan para ahli dalam menentukan parameter untuk penentuan prioritas rencana penanganan genangan air. Adapun struktur hierarkinya pada Gambar 3.

UNITEK Vol 12 No.1 Januari - Juni 2019 | p-ISSN 2089-3957 | e-ISSN 2580-2585 


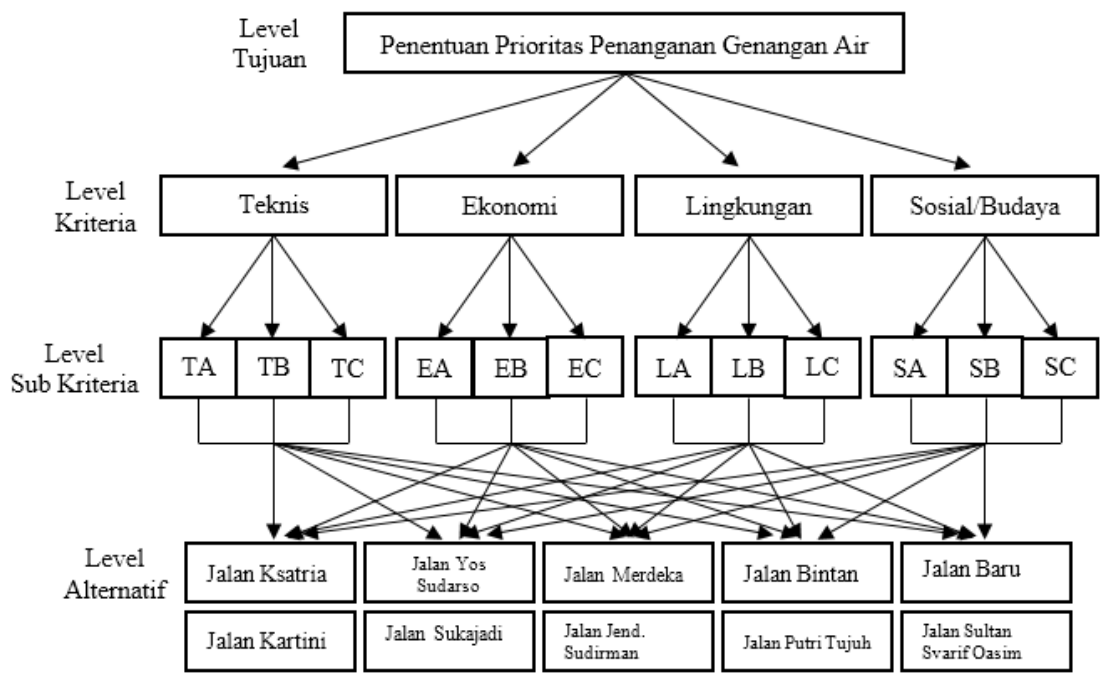

Gambar 3. Hierarki parameter signifikan dalam penentuan prioritas rencana penanganan genangan air kota Dumai

Langkah awal dalam analisis ini adalah memasukkan nilai kriteria-kriteria yang ada dalam kuisioner detail, yaitu teknis, ekonomi, lingkungan dan sosial/budaya kedalam Software Expert Choice 2000. Misalnya: teknis vs ekonomi $=5$ (kriteria teknis jelas lebih penting daripada kriteria ekonomi), teknis vs lingkungan $=3$ (kriteria teknis sedikit lebih penting daripada kriteria lingkungan), teknis vs sosial/budaya $=5$ (kriteria teknis jelas lebih penting daripada kriteria sosial/budaya). Pada Software Expert Choice 2000, nilai-nilai yang merupakan kebalikan dari perbandingan tiap kriteria secara otomatis akan diberi warna merah seperti Gambar 4.

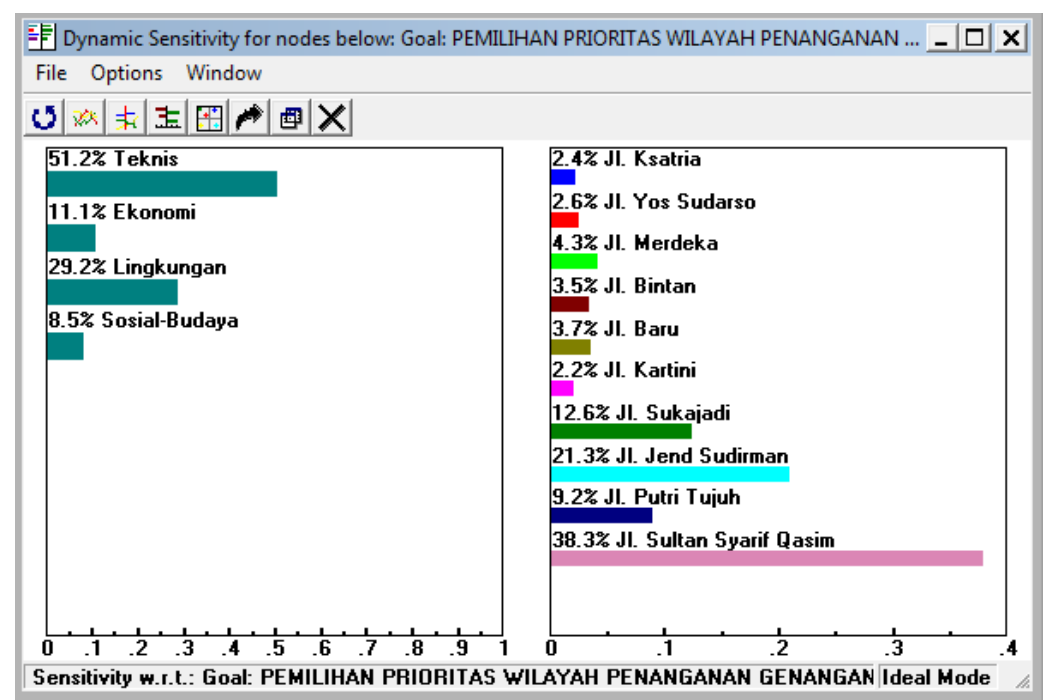

Gambar 4. Tingkat Kriteria yang Paling Mempengaruhi Dalam Penentuan Prioritas Rencana Penanganan Genangan Air Kota Dumai

UNITEK Vol 12 No.1 Januari - Juni 2019 | p-ISSN 2089-3957 | e-ISSN 2580-2585 
Berdasarkan Gambar 4, analisis kriteria yang memiliki prioritas (tingkat) paling mempengaruhi terhadap penentuan prioritas penanganan wilayah genangan yaitu kriteria Teknis, 51,2\% ; Lingkungan 29,2\% ; Ekonomi 11,1\% ; dan Sosial Budaya 8,5\% dari total kriteria yang ada. Sedangkan untuk pemulihan subkriteria signifikan dapat dilihat pada Gambar 5.

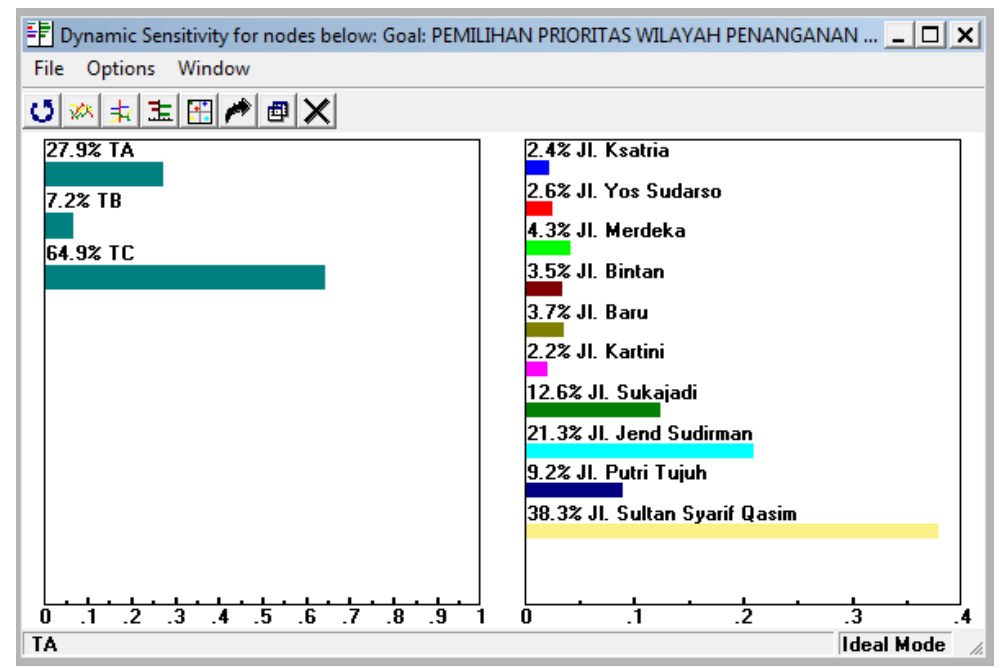

Gambar 5. Tingkat Parameter Subkriteria Teknis yang mempengaruhi Penentuan Prioritas Rencana Penanganan Genangan Air Kota Dumai

Berdasarkan Gambar 5, analisis sub kriteria teknis yang memiliki prioritas (tingkat) paling mempengaruhi terhadap penentuan prioritas penentuan prioritas wilayah penangan genangan air yaitu perubahan tata guna lahan sebesar 64,9\%, kondisi fisik dan fungsi drainase 27,9\% dan kapasitas jaringan drainase 7,2\%. Sedangkan untuk Sub Kriteria Ekonomi dapat dilihat pada Gambar 6.

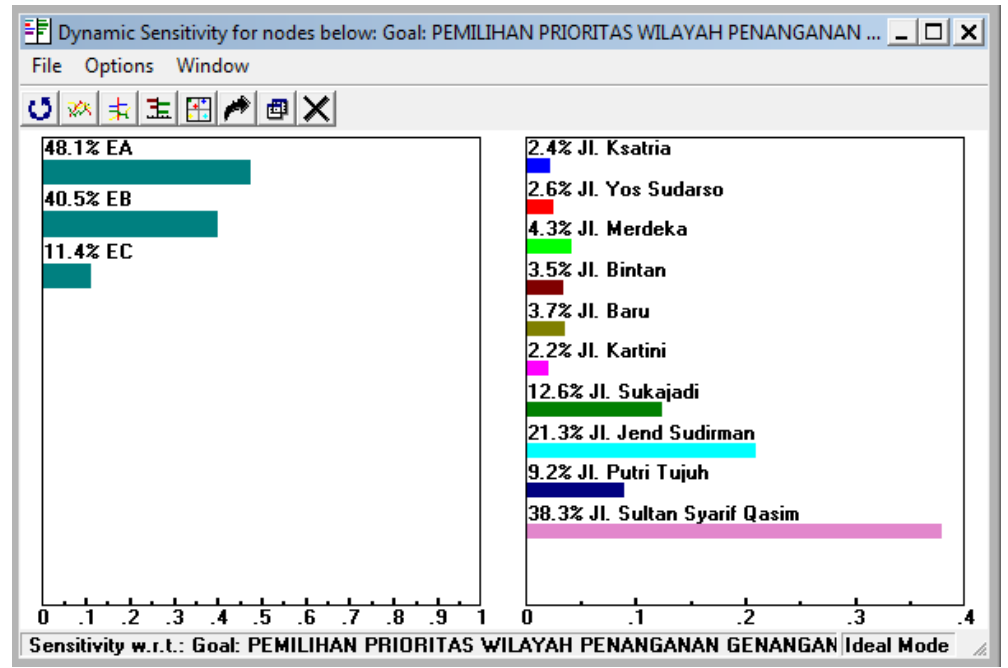

Gambar 6. Tingkat parameter subkriteria ekonomi yang mempengaruhi penentuan prioritas rencana penanganan genangan air kota Dumai

UNITEK Vol 12 No.1 Januari - Juni 2019 | p-ISSN 2089-3957 | e-ISSN 2580-2585 
Berdasarkan Gambar 6, analisis sub kriteria ekonomi yang memiliki prioritas (tingkat) paling mempengaruhi terhadap penentuan prioritas wilayah penanganan genangan air yaitu Biaya Pekerjaan Pembangunan Sistem Drainase sebesar 48,1\% ; Ketersediaan Dana Operasi \& Pemeliharaan Tahunan Sistem Drainase sebesar 40,5\% dan Biaya Evaluasi Monitoring Tahunan Sistem Drainase sebesar 11,4\%. Sedangkan untuk Sub Kriteria Lingkungan dapat dilihat pada Gambar 7.

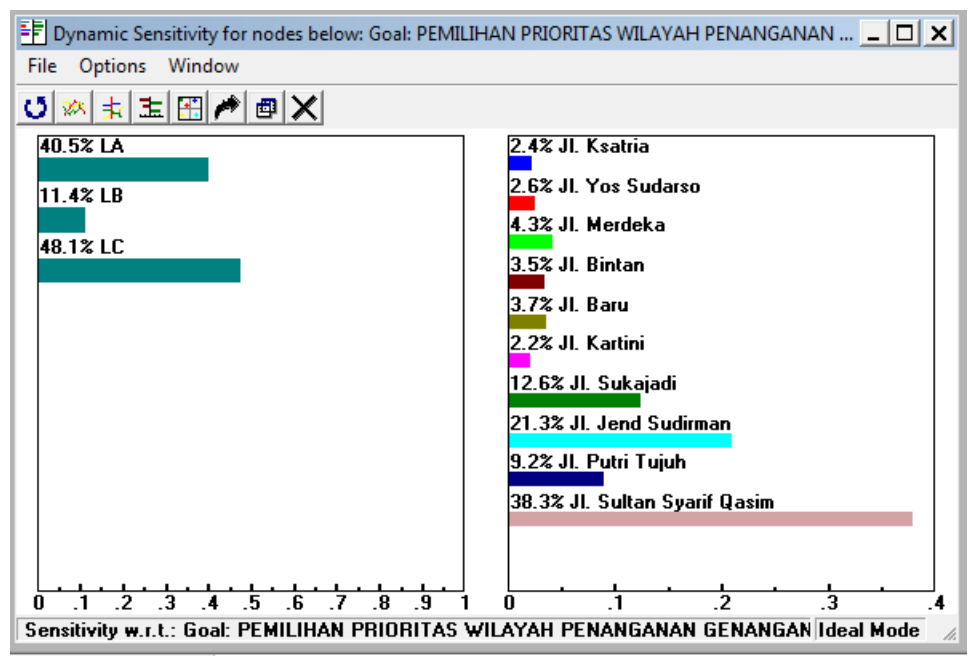

Gambar 7. Tingkat Parameter Subkriteria Lingkungan yang mempengaruhi Penentuan Prioritas Rencana Penanganan Genangan Air Kota Dumai

Berdasarkan Gambar 7, analisis sub kriteria lingkungan yang memiliki prioritas (tingkat) paling mempengaruhi terhadap penentuan prioritas wilayah penanganan genangan air yaitu volume sampah sebesar $48,1 \%$; sanitasi lingkungan sebesar 40,5\% dan luas daerah layanan sebesar 11,4\%. Sedangkan untuk Sub Kriteria Sosial/Budaya pada Gambar 8.

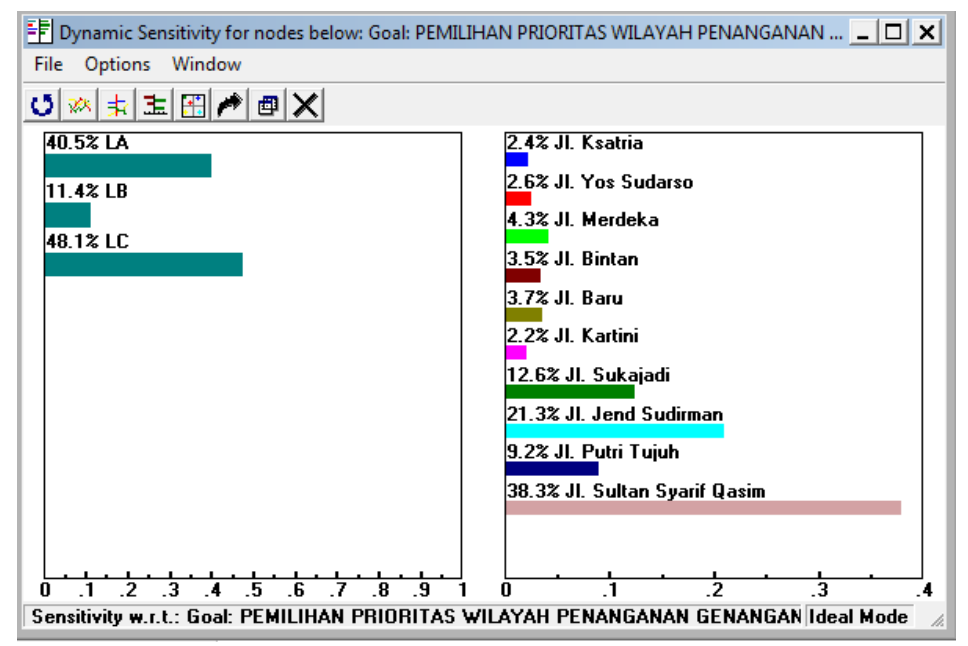

Gambar 8. Tingkat parameter subkriteria sosial/budaya yang mempengaruhi penentuan prioritas rencana penanganan genangan air kota Dumai

UNITEK Vol 12 No.1 Januari - Juni 2019 | p-ISSN 2089-3957 | e-ISSN 2580-2585 
Berdasarkan Gambar 8, analisis sub kriteria sosial/budaya yang memiliki prioritas (tingkat) paling mempengaruhi terhadap penentuan prioritas Penanganan Genangan Air adalah Penegakan hukum/aturan sebesar 48,1\% ; Pengelolaan dan Pemeliharaan Prasarana Drainase sebesar 40,5 dan Perilaku membuang sampah sembarangan sebesar $11,4 \%$. Kriteria parameter yang memiliki prioritas (tingkat) paling mempengaruhi terhadap penentuan prioritas wilayah penanganan genangan air adalah kriteria teknis (42,7\%) dan kriteria lingkungan (29,2\%). Sedangkan kriteria ekonomi dan kriteria sosial/budaya dipandang perlu namun masih dibawah dari kriteria lingkungan dan kriteria teknis seperti Gambar 9.

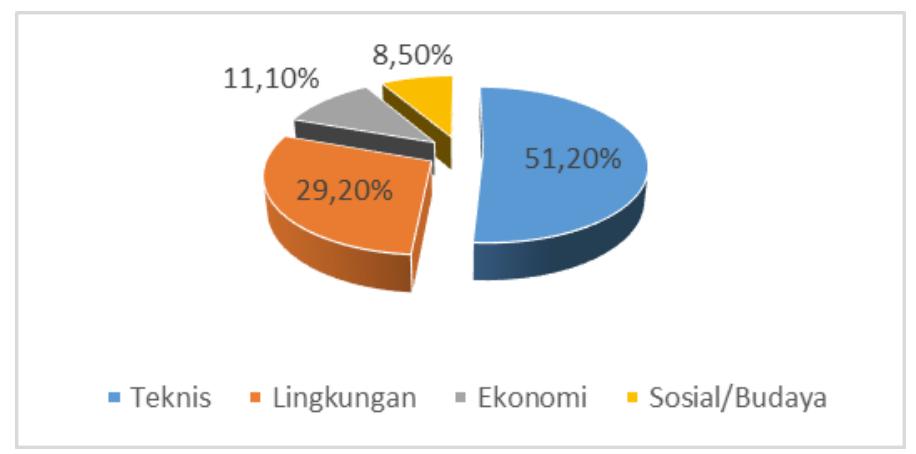

Gambar 9. Persentase Kriteria Parameter Dalam Penentuan Prioritas Wilayah Penanganan Genangan Air

Ringkasan dari yang diuraikan tersebut adalah sebagai berikut ini.

1. Sub kriteria parameter yang paling berpengaruh dalam penentuan prioritas wilayah penanganan genangan air dapat dilihat pada Gambar 10.

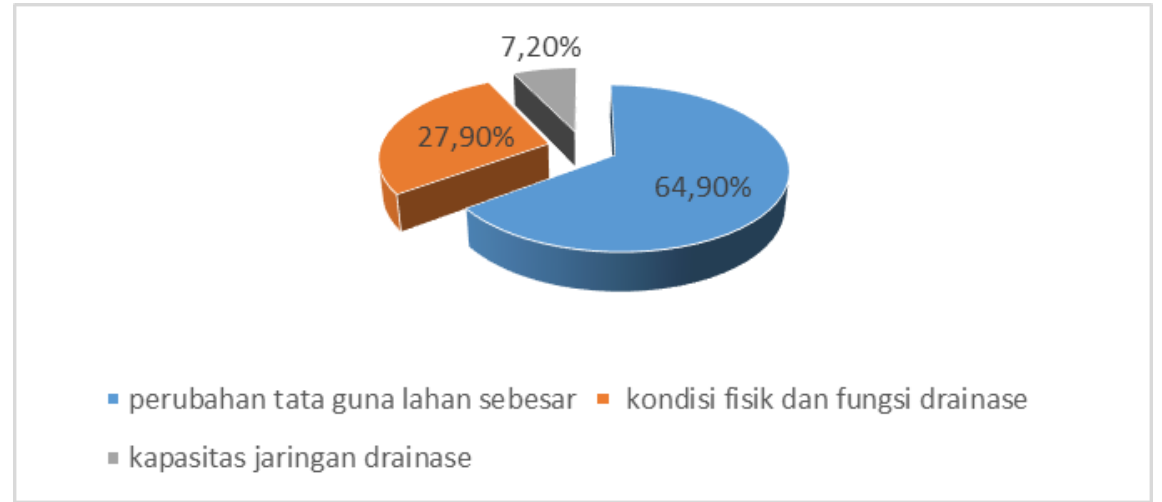

Gambar 10. Tingkat Pengaruh Sub Kriteria Teknis Dalam Penentuan Prioritas Penanganan Wilayah Genangan.

Berdasarkan Gambar 10, dapat diketahui bahwa dalam penentuan prioritas wilayah penanganan genangan air sub kriteria perubahan tata guna lahan mempunyai tingkat pengaruh yang paling besar yaitu sebesar $64,9 \%$. Artinya pengaruh alih fungsi lahan merupakan faktor utama penyebab tingginya permasalahan genangan air di Kota Dumai. Berdasarkan hasil analisa Analytical Hierarchy Process (AHP), diperoleh wilayah terbaik untuk rencana

UNITEK Vol 12 No.1 Januari - Juni 2019 | p-ISSN 2089-3957 | e-ISSN 2580-2585 
penanganan genangan Air di Kota Dumai adalah Jalan Sultan Syarif Qasim dengan persentase sebesar $38,3 \%$.

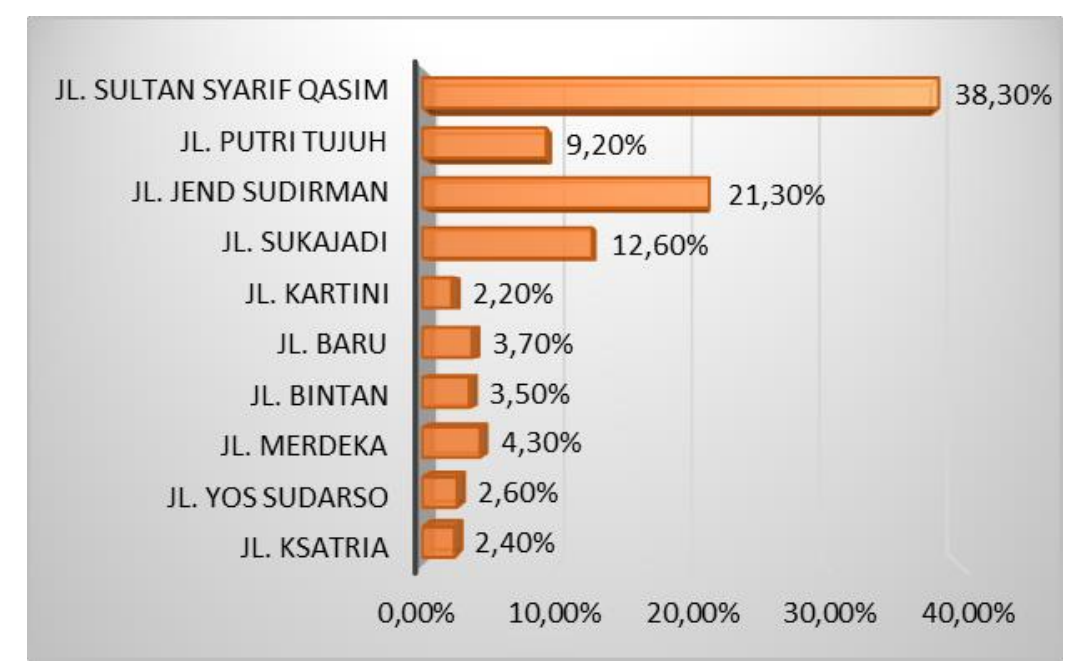

Gambar 11. Persentase Prioritas Wilayah Penanganan Genangan Air Kota Dumai

\section{Mitigasi Penanganan Genangan Air di Wilayah yang Menjadi Prioritas}

Pemecahan masalah genangan dibedakan dalam 2 metode, yaitu metode pencegahan/preventif dan metode penyembuhan. Kedua metode tersebut kadang tidak dapat dibedakan secara jelas, karena dapat saja ditafsirkan sebagai metode pencegahan namun dapat pula ditafsirkan sebagai metode penyembuhan. Sebagai contoh masalah sampah, penegakan hukum terhadap pelanggaran Perda No.4/2000 tentang Retribusi Kebersihan dapat dianggap sebagai penerapan metode pencegahan, tetapi pengangkatan dan pengangkutan sampah dari saluran drainase dapat dianggap sebagai metode penyembuhan.

Metode Pencegahan I Preventif

Metode ini dilaksanakan untuk mencegah atau mengurangi terjadinya genangan yang lebih luas dikemudian hari. Penerapan metode ini dapat dilaksanakan sebagaimana tercantum di bawah ini :

1. Perkembangan pembangunan sarana perkotaan telah menyebabkan, berkurangnya lahan menyerap air hujan (infiltrasi) karena lahan yang dulunya terbuka menjadi tertutup sehingga menambah lahan kedap air. Akibatnya volume air limpasan meningkat. Demikian juga adanya penambahan aktifitas dalam sarana perkotaan volume air limbah akan meningkat. Sarana drainase yang ada mungkin tidak mampu lagi menampung air limpasan dan air limbah. Untuk mengurangi dampak lebih lanjut akibat hal-hal tersebut diatas perlu ada upaya sebagai berikut :

a. Mempertahankan lahan terbuka yang mampu menyerap air hujan yaitu :

- Daerah tangkapan hujan (catchment area)

- $\quad$ Paru-paru kota dan keseimbangan kota

- Kawasan pertanian dan hutan produksi

UNITEK Vol 12 No.1 Januari - Juni 2019 | p-ISSN 2089-3957 | e-ISSN 2580-2585 
- Kawasan penyangga (buffer zone) yang berupa jalur hijau (green belt atau green area)

Kawasan lindung

- Kawasan terbuka lain seperti areal pemakaman, halaman luas dikantor pemerintah, kawasan olahraga, kawasan rekreasi dan lain-lain.

b. Mengawasi secara ketat penyimpangan Koe/isien Dasar Bangunan. Penyimpangan ini umumnya mengarah pada pengurangan lahan diluar bangunan sehingga akan mengurangi luas lahan terbuka.

c.Meningkatkan kemampuan lahan menyerap air hujan pada kawasan terbangun dengan pembuatan sumur resapan, penggunaan blok beton pejal maupun berlubang pada areal parkir, jalan masuk perumahan, jalan kampung dan lain-lain.

d. Mengurangi air limpasan dengan membangun :

Kolam tandon sementara (food adjusment pond) dikawasan parkir yang luas. Kolam tandon ini pada bagian pinggirnya dibatasi tembok kedap air namun diberi lubang-lubang pembuangan air dengan ketinggian lubang bergradasi, agar pengeluaran air dari kolam tersebut dapat mengalir secara bergilir sesuai dengan elevasi air yang ditampung. Ketinggian air dalam kolam ini lebih kurang $20 \mathrm{~cm}$ dimana lubang buangan (knalpot) mobil tidak tertutup oleh air genangan.

2. Sarana drainase berkurang karena adanya endapan dan sampah. Sampah ini dapat terangkut ke dalam sarana drainase secara alami karena jatuh dari pohon tetapi dapat pula karena ketidak pahaman penduduk yang kurang menyadari akibat lebih lanjut merugikan.

3. Penyuluhan kepada masyarakat agar tidak membuang sampah kedalam saluran drainase, perlu ditingkatkan dan dilaksanakan secara terus menerus, sesuai dengan Perda setempat (jika ada) tentang Restribusi Kebersihan bahwa pelanggaran tentang hal ini dapat dikenai sanksi hukum. Kebersihan saluran drainase tidak hanya menjadi tanggung jawab Pemerintah Daerah tetapi juga oleh masyarakat. Karena masyarakat kita masih bersifat paternalistik maka dipandang perlu untuk diberi contoh tentang kebersihan lingkungan oleh para tokoh masyarakat. Jika perlu ditetapkan adanya hari bersih yang dilaksanakan masing-masing lingkungannya termasuk kebersihan sarana drainasenya. Hari bersih dapat dilaksanakan satu minggu sekali atau satu bulan sekali. Yang perlu menjadi perhatian adalah sesegera mungkin mengangkut sampah agar sampah tersebut tidak masuk lagi kedalam saluran drainase.

Perlu menyediakan bak-bak sampah yang cukup dan mudah dijangkau. Agaknya pengelolaan sampah perlu ditingkatkan agar tidak terjadi penumpukan sampah diseluruh wilayah. Peningkatan pendidikan serta kesejahteraan penduduk harus menjadi perhatian. Karena penduduk yang terdidik serta tingkat kesejahteraan yang memadai, umumnya lebih mudah untuk diajak menjaga I merawat fasilitas umum termasuk sarana drainase.

UNITEK Vol 12 No.1 Januari - Juni 2019 | p-ISSN 2089-3957 | e-ISSN 2580-2585 
4. Operasi dan pemeliharaan harus ditingkatkan baik kualitas maupun kuantitasnya.

Pemeliharaan sarana drainase yang ada kurang memadai. Hampir seluruh saluran drainase dan bangunan pelengkapnya dipenuhi endapan dan sampah. Dibeberapa tempat penutup trotoar I saluran tertutup banyak yang rusak. Kondisi ini disamping membahayakan keselamatan pejalan kaki, lubang yang ada tersebut dapat merupakan tempat orang membuang sampah.

\section{Perencanaan Penanganan Genangan}

Sebagian besar permasalahan genangan disebabkan oleh kondisi topografi Kota Dumai yang relatif datar, kondisi topografi ini merupakan hal yang penting untuk menentukan arah aliran drainase. Genangan genangan terjadi pada daerah kota di Jl Sutan Syarif kasim dan sekitarnya, disebabkan oleh kapasitas saluran yang sudah tidak bisa menampung limpasan air hujan. Oleh karena itu kapasitas saluran yang ada harus didesain sehingga dapat menampung debit air yang ada.

\section{Saluran drainase bentuk trapesium}

Pada umumnya saluran tanah, namun dimungkinkan juga bentuk ini dari pasangan batu atau beton. Saluran ini membutuhkan ruang atau lahan yang cukup dan berfungsi untuk pengaliran air hujan, air rumah tangga maupun air irigasi. Saluran ini merupakan saluran serba guna yang sering digunakan karena mudah dalam pengerjaannya. Saluran ini juga dapat menampung volume air yang besar dan disamping itu mudah dalam pengerjaannya.

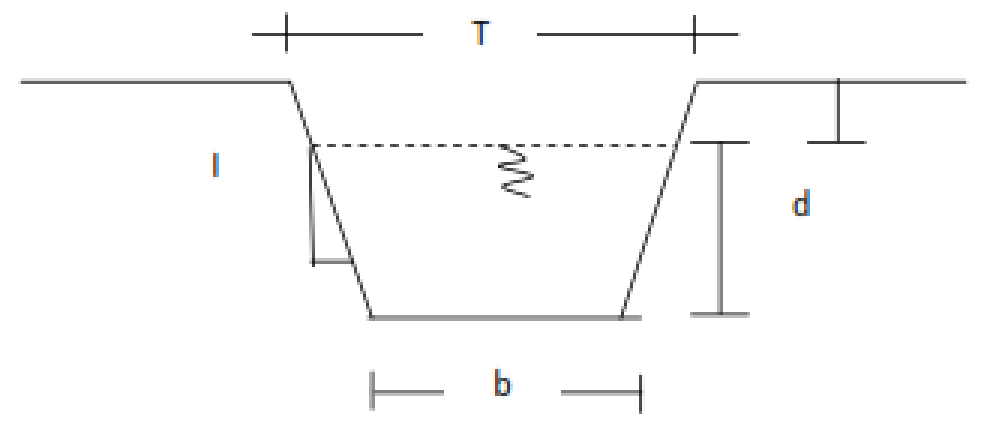

Dimana :

$$
\begin{array}{ll}
\text { Luas (A) } & =(\mathrm{b}+\mathrm{zh}) \mathrm{h} \\
\text { Keliling basah (P) } & =b+2 h \sqrt{1+z^{2}} \\
\text { Jari }- \text { jari hidrolik (R) }=\mathrm{A} / \mathrm{P} & \\
\text { Lebar puncak (T) } & =\mathrm{b}+2 \mathrm{zh} \\
\text { Kedalaman hidrolis (D) } & =\frac{(b+z h) h}{b+2 z h} \\
\text { Faktor penampang (Z) }=\frac{\{(b+z h) h\}}{\sqrt{b+2 z h}}
\end{array}
$$

Kemiringan talud tergantung dari besarnya debit, dapat dilihat pada Tabel berikut.

UNITEK Vol 12 No.1 Januari - Juni 2019 | p-ISSN 2089-3957 | e-ISSN 2580-2585 
Tabel 4. Hubungan debit dengan talud

\begin{tabular}{|c|c|}
\hline Debit Air Q (M3/detik) & Kemiringan Talud \\
\hline $0.00-0.75$ & $1: 1$ \\
\hline $0.75-15$ & $1: 1.5$ \\
\hline $15-80$ & $1: 2$ \\
\hline
\end{tabular}

Sumber : SNI 03-3424-1994

Adapun rencana perlebaran drainase Kota Dumai pada wilayah yang menjadi prioritas dapat dilihat sebagai berikut.

Tabel 5. Perhitungan Dimensi Saluran Drainase Kota Dumai (Saluran Primer/S dan Saluran Pembuang/P)

\begin{tabular}{|c|c|c|c|c|c|c|c|c|c|c|c|c|c|c|c|}
\hline \multirow{2}{*}{ No. } & \multirow{2}{*}{$\begin{array}{l}\text { Nama } \\
\text { Saluran }\end{array}$} & \multirow{2}{*}{$\begin{array}{c}\text { Areal } \\
\text { Tangkapan } \\
\text { (Ha) }\end{array}$} & \multirow[t]{2}{*}{ C } & I & Panjang & \multirow[t]{2}{*}{ i } & \multirow{2}{*}{$\begin{array}{c}\text { B } \\
(\mathrm{m})\end{array}$} & \multirow{2}{*}{$\begin{array}{l}K \\
= \\
60\end{array}$} & \multirow{2}{*}{$\begin{array}{c}R= \\
0,25 * b\end{array}$} & \multirow{2}{*}{$\begin{array}{c}V= \\
\text { K.R }{ }^{2 / 3} \cdot I^{1 / 2} \\
(\mathbf{m} / \mathbf{d t})\end{array}$} & \multirow{2}{*}{$\begin{array}{c}Q=C . I . A \\
\left(m^{3} / d t\right)\end{array}$} & \multirow{2}{*}{$\begin{array}{l}\text { Tinggi } \\
\text { (h) }\end{array}$} & \multirow{2}{*}{$\begin{array}{c}\text { F (luas } \\
\text { saluran) } \\
\text { b.h }\end{array}$} & \multirow{2}{*}{$\begin{array}{c}\text { Q Kap }= \\
\text { V.F }\end{array}$} & \multirow{2}{*}{$\begin{array}{c}\begin{array}{c}\text { Ukuran } \\
\text { b/ht }\end{array} \\
\text { ht }=\mathbf{h}+30 \mathrm{~cm} \\
\end{array}$} \\
\hline & & & & (mm/jam) & (m) & & & & & & & & & & \\
\hline 1. & $\begin{array}{l}\text { Jl. Sultan } \\
\text { Syarif } \\
\text { Kasim } \\
\end{array}$ & 120 & 0,7 & 20,92 & 1200 & 0,001 & 2,5 & 60 & 0,625 & 0,0039 & 0,084 & 4,88 & 12,2 & 0,0476563 & $2,5 \times 1,6$ \\
\hline 2. & $\begin{array}{l}\text { Jl. Jend. } \\
\text { Sudirman }\end{array}$ & 44 & 0,8 & 20,92 & 1428 & 0,0012 & 2,5 & 60 & 0,625 & 0,0047 & 0,04224 & 1,3 & 3,25 & 0,0152344 & $2,5 \times 1,6 \mathrm{~m}$ \\
\hline 3. & $\begin{array}{l}\text { Jl. } \\
\text { Sukajadi }\end{array}$ & 72 & 0,7 & 30 & 1160 & 0,0012 & 2,5 & 60 & 0,625 & 0,0047 & 0,06048 & 1,3 & 3,25 & 0,0152344 & $2,5 \times 1,6 \mathrm{~m}$ \\
\hline
\end{tabular}

Tabel 6. Rencana pembuatan dan pelebaran saluran

\begin{tabular}{|c|l|c|c|c|}
\hline No. & \multicolumn{1}{|c|}{$\begin{array}{c}\text { Daerah } \\
\text { Genangan }\end{array}$} & $\begin{array}{c}\text { Dimensi Pelebaran } \\
\text { Saluran }\end{array}$ & $\begin{array}{c}\text { Panjang } \\
\text { Saluran }\end{array}$ & $\begin{array}{c}\text { Prioritas } \\
\text { Berdasarkan AHP }\end{array}$ \\
\hline 1. & $\begin{array}{l}\text { Jl. Sultan Syarif } \\
\text { Kasim }\end{array}$ & $2,5 \times 1,6 \mathrm{~m}$ & 1200 & 1 \\
\hline 2. & $\begin{array}{l}\text { Jl. Jend. } \\
\text { Sudirman }\end{array}$ & $2,5 \times 1,6 \mathrm{~m}$ & 1428 & 2 \\
\hline 3. & Jl. Sukajadi & $2,5 \times 1,6 \mathrm{~m}$ & 1160 & 3 \\
\hline
\end{tabular}

\section{Simpulan}

Dari hasil penelitian yang telah dilakukan, maka dapat disimpulkan hal-hal seperti berikut ini :

1. Kriteria parameter yang memiliki prioritas (tingkat) paling mempengaruhi terhadap penentuan prioritas wilayah penanganan genangan air adalah kriteria teknis $(42,7 \%)$ dan kriteria lingkungan $(29,2 \%)$. Sedangkan kriteria ekonomi dan kriteria sosial/budaya dipandang perlu namun masih dibawah dari kriteria lingkungan dan kriteria teknis

2. Sub kriteria parameter yang paling berpengaruh dalam penentuan prioritas wilayah penanganan genangan air adalah perubahan tata guna lahan dengan persentase sebesar $64,9 \%$

3. Berdasarkan hasil analisa Analytical Hierarchy Process (AHP), diperoleh wilayah terbaik untuk rencana penanganan genangan air di Kota Dumai adalah Jalan Sultan Syarif Qasim dengan persentase sebesar 38,3\%.

4. Upaya yang dilakukan untuk penanganan genangan drainase di Jl. Sultan Syarif Qasim adalah dengan memperbaiki sistem drainase eksisting dengan dimensi $2,5 \times 1,6 \mathrm{~m}$.

UNITEK Vol 12 No.1 Januari - Juni 2019 | p-ISSN 2089-3957 | e-ISSN 2580-2585 
Berdasarkan hasil penelitian ini, maka saran-saran yang dapat penulis berikan seperti berikut ini:

1. Perubahan tata guna lahan untuk peruntukkan lahan yang baru harus dilakukan berdasarkan kajian-kajian yang sudah ada.

2. Perlu diteliti lebih lanjut tentang alih fungsi lahan di Kota Dumai untuk memprediksi wilayah mana yang akan terjadi genangan.

\section{Daftar Pustaka}

Dirjen Cipta Karya. (2011). Master Plan dan DED Drainase Kabupaten Karanganyar. Laporan Akhir. Semarang.

Helfira, N. (2013). Identifikasi Parameter dalam Penentuan Prioritas Penanganan Masalah Sistem Drainase di Wilayah Kota Pekanbaru Menggunakan Metode Analytical Hierarcy Process (AHP). Tugas Akhir Strata-1. Program Studi S-1 Teknik Sipil Universitas Riau.

Ismail, H. (2011). Prioritas Rehabilitasi Sistem Drainase Mikro Daerah Aliran Sungai (DAS) Kali Pepe Hulu Kota Surakarta. Skripsi. Universitas Sebelas Maret Surakarta.

Mairimin. (2004). Pengambilan Keputusan Kriteria Majemuk: Penerbit PT Grasindo.

Muttaqien, A. Y. (2006). Kinerja Sistem Drainase yang Berkelanjutan Berbasis Partisipasi Masyarakat. Tesis. Universitas Diponegoro Semarang.

Muttaqien, A. Y. (2008). Metode AHP Untuk Penyusunan Sistem Pendukung Keputusan. Universitas Sebelas Maret Surakarta.

Muttaqin, A. Y. (2007). Sistem Pendukung Kebijakan Prioritas Revitalisasi Jaringan Drainase Dengan Pendekatan AHP Pada Sistem Drainase Surakarta Bagian Utara. Laporan Penelitian. Surakarta.

Rahmi. (2013). Identifikasi Parameter Optimalisasi Penggunaan Air Irigasi Berdasarkan Analytical Hierarchy Process (Studi Kasus Daerah Irigasi Muara Jalai Kabupaten Kampar). Skripsi. Fakultas Teknik Universitas Riau.

Saaty, T.L. (1993). Pengambilan Keputusan Bagi Para Pemimpin, Proses Hirarki Analitik untuk Pengambilan keputusan dalam Situasi yang Kompleks. Jakarta: PT. Pustaka Binaman pressindo.

Suripin. (2004). Sistem Drainase Perkotaan yang Berkelanjutan. Andi: Yogjakarta.

Suryanto, F. (2011). Analisis Faktor yang Mempengaruhi Kinerja Sistem Drainase Mikro DAS Jurug-Bengawan Solo Berdasarkan Pendekatan AHP. Skripsi. Universitas Sebelas Maret Surakarta.

UNITEK Vol 12 No.1 Januari - Juni 2019 | p-ISSN 2089-3957 | e-ISSN 2580-2585 